\title{
Reuna
}

\section{MÍDIAS SOCIAIS EM TURISMO E HOTELARIA: UMA REVISÃO DAS PESQUISAS PUBLICADAS ENTRE 2006 E 2017}

\section{SOCIAL MEDIA IN TOURISM AND HOSPITALITY: A REVIEW OF RESEARCH PUBLISHED BETWEEN 2006 AND 2017}

http://dx.doi.org/10.21714/2179-8834/2019v24n3p64-79

\author{
Francieli Boaria \\ Universidade Federal do Rio Grande (FURG), Brasil. \\ E-mail: franboaria@gmail.com \\ Ademilso Alves da Cunha \\ Universidade Federal do Rio Grande (FURG), Brasil. \\ E-mail: ademilsoalves@yahoo.com.br
}

Submissão: 17 Out. 2018 Publicação: 02 Nov. 2019. Sistema de avaliação: Double blind review. Centro Universitário UNA, Belo Horizonte - MG, Brasil. Editor geral: Prof. Dr. Gustavo Quiroga Souki

Este artigo encontra-se disponível nos seguintes endereços eletrônicos:

http://revistas.una.br/index.php/reuna/article/view/1048

http://dx.doi.org/10.21714/2179-8834/2019v24n3p64-79

\section{Resumo}

Ao influenciar as intenções no planejamento de viagem e na compra de produtos e serviços, as mídias sociais desempenham um papel proeminente no turismo e hotelaria devido ao seu aspecto intangível antes do consumo. Elas funcionam como um termômetro, pois suas ferramentas podem auxiliar o mercado na mensuração e condução de segmentos no setor. Este trabalho conduz uma revisão bibliográfica de todas as investigações sobre as mídias sociais nas áreas de turismo e hotelaria publicadas em âmbito nacional e internacional até o ano de 2017. Foram identificadas cinco variáveis principais, incluindo as características das mídias sociais, a interação entre consumidores e clientes, os impactos resultantes da utilização das mídias sociais pelas empresas e consumidores, a relação interpessoal online decorrente do conteúdo gerado pelo consumidor e, a personalização. Este artigo contribui para a teoria, o conhecimento e a prática profissional resultante dessas publicações, além de trazer estudos de tendências futuras.

Palavras-chave: Mídias sociais; Turismo; Hotelaria; Internet. 


\section{Abstract}

By influencing intentions in travel planning and buying products and services, social media plays a prominent role in tourism and hospitality because of its intangible appearance before consumption. Social media works like a thermometer because their tools can help the market in measuring and driving segments in the industry. This paper leads to a bibliographical review of all research on social media in the tourism and hospitality fields published nationally and internationally until 2017 . Five main variables were identified, including the characteristics of social media, the interaction between consumers and customers, the impacts resulting from the use of social media by companies and consumers, the online interpersonal relationship resulting from the user generated content and, personalization. This paper contributes to the theory, knowledge and professional practice resulting from these publications, as well as to bring studies of future trends.

Keywords: Social media; Tourism; Hotel; Internet.

\section{Introdução}

A tecnologia da informação e comunicação (TICs) tem progredido de maneira veloz desde o início dos anos 2000 devido ao desenvolvimento das variedades de serviços e ferramentas que viabilizam a comunicação e compartilhamento de informações entre empresas e consumidores em todo o planeta. Novas percepções e funcionalidades das TICs foram sendo implantadas no cotidiano dos indivíduos, onde turismo e tecnologia descobriram que podem percorrer caminhos lado a lado, trazendo alterações cruciais tanto para o mercado quanto para a rotina dos indivíduos. Buhalis (1998) destaca que não apenas as TICs capacitam os consumidores a identificar, personalizar e comprar produtos turísticos, mas também apoiam a globalização do setor, provendo ferramentas eficazes para que os fornecedores desenvolvam, gerenciem e distribuam suas ofertas em todo o mundo. Em decorrência disto, surge uma expressiva área de investigação à medida que os pesquisadores procuram cada vez mais entender e comunicar a relevância das tecnologias, investigar e interpretar a atividade moderna e tentar prever o caminho a ser seguido tanto para o mercado quanto para os desenvolvimentos tecnológicos.

Neste aspecto, O'Connor e Murphy (2004) revisaram pesquisas sobre TICs no setor de hospitalidade e revelaram três amplas áreas de pesquisa: (1) os efeitos da internet na distribuição; (2) na precificação; e (3) nas interações do consumidor. Quanto ao terceiro item, o qual conversa com este trabalho, um estudo da eMarketer (2018) estimou que em 2017 uma em cada três pessoas, equivalente a cerca de 2,48 bilhões no mundo inteiro usou uma rede social, apresentando um número acentuado de usuários nas redes sociais. O mesmo estudo demonstrou o aumento do uso de redes sociais nos mercados emergentes na Ásia-Pacífico, América Latina, Oriente Médio e África, com um crescimento de 8,7\% em relação ao ano de 2016. Por ter forte relevância para as pesquisas, esta investigação bibliográfica busca realizar um levantamento de publicações sobre mídias sociais na área de turismo e hotelaria apresentando as principais variáveis, em uma linha do tempo de 11 anos (de 2006 a 2017), além de trazer perspectivas futuras para o setor. 
Uma abordagem de revisão sistemática foi adotada neste estudo para analisar pesquisas sobre as mídias sociais no turismo e na hotelaria. A coleta de dados foi realizada nos meses de julho a dezembro de 2017. Foram escolhidos para a análise apenas artigos completos publicados em revistas acadêmicas e periódicos científicos sobre o tema. Todas as publicações relacionadas às mídias sociais encontradas em revistas de turismo e hotelaria nacionais e internacionais foram pesquisadas e coletadas em diferentes bases de dados online, a citar: EBSCOHost, Science Direct, Scielo, Springer, bem como o mecanismo de busca Google Scholar, e todas as revistas e os anais de eventos da área mais conhecidos no Brasil, conforme apresenta-se na Tabela 1.

Tabela 1 - Artigos nacionais sobre mídias sociais no turismo e hotelaria.

\begin{tabular}{|c|c|c|c|c|c|}
\hline Revista & \multicolumn{2}{|c|}{$\begin{array}{l}\text { Quantidade de } \\
\text { artigos e ano de } \\
\text { publicação }\end{array}$} & \multirow{6}{*}{$\begin{array}{l}\text { Anais de Eventos } \\
\text { Fórum Internacional de } \\
\text { Turismo do Iguassu }\end{array}$} & \multicolumn{2}{|c|}{$\begin{array}{l}\text { Quantidade de } \\
\text { artigos e ano de } \\
\text { publicação }\end{array}$} \\
\hline \multirow{5}{*}{$\begin{array}{l}\text { RBTUR - Revista } \\
\text { Brasileira de } \\
\text { Pesquisa em Turismo }\end{array}$} & \multirow{3}{*}{2} & \multirow{3}{*}{2014} & & 1 & 2010 \\
\hline & & & & 3 & 2012 \\
\hline & & & & 1 & 2013 \\
\hline & \multirow{2}{*}{1} & \multirow{2}{*}{2015} & & 2 & 2015 \\
\hline & & & & 6 & 2016 \\
\hline \multirow{5}{*}{$\begin{array}{l}\text { CULTUR - Revista de } \\
\text { Cultura e Turismo }\end{array}$} & \multirow{5}{*}{1} & \multirow{5}{*}{2015} & \multirow{5}{*}{$\begin{array}{l}\text { ANPTUR - Seminário da } \\
\text { Associação Nacional } \\
\text { Pesquisa e Pós-Graduação } \\
\text { em Turismo }\end{array}$} & 2 & 2012 \\
\hline & & & & 3 & 2013 \\
\hline & & & & 1 & 2014 \\
\hline & & & & 4 & 2015 \\
\hline & & & & 2 & 2016 \\
\hline \multirow{2}{*}{$\begin{array}{l}\text { Caderno Virtual de } \\
\text { Turismo }\end{array}$} & 1 & 2015 & \multirow{2}{*}{$\begin{array}{l}\text { CIAH - Ciclo Internacional } \\
\text { de Atividades Hoteleiras }\end{array}$} & \multirow{2}{*}{1} & \multirow{2}{*}{2013} \\
\hline & 1 & 2016 & & & \\
\hline \multirow{2}{*}{$\begin{array}{l}\text { Marketing \& Tourism } \\
\text { Review }\end{array}$} & 1 & 2017 & \multirow{2}{*}{$\begin{array}{l}\text { Semintur - Seminário de } \\
\text { Pesquisa em Turismo do } \\
\text { Mercosul }\end{array}$} & \multirow{2}{*}{1} & \multirow{2}{*}{2006} \\
\hline & 1 & 2017 & & & \\
\hline \multirow[b]{2}{*}{ Revista Hospitalidade } & 1 & 2012 & \multirow{2}{*}{$\begin{array}{l}\text { Semintur JR - Seminário de } \\
\text { Pesquisa em Turismo do } \\
\text { Mercosul }\end{array}$} & 2 & 2014 \\
\hline & 1 & 2014 & & 1 & 2015 \\
\hline \multirow{2}{*}{$\begin{array}{l}\text { Revista Rosa dos } \\
\text { Ventos }\end{array}$} & 1 & 2013 & \multirow[b]{2}{*}{$\longrightarrow$} & \multirow[b]{2}{*}{-} & \multirow[b]{2}{*}{-} \\
\hline & 1 & 2015 & & & \\
\hline $\begin{array}{l}\text { Revista Turismo - } \\
\text { Visão e Ação }\end{array}$ & 1 & 2015 & & - & - \\
\hline $\begin{array}{l}\text { Revista Turismo em } \\
\text { Análise }\end{array}$ & 1 & 2017 & & - & - \\
\hline $\begin{array}{l}\text { Revista Cadernos de } \\
\text { Aulas do LEA }\end{array}$ & 1 & 2013 & & - & 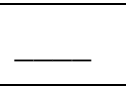 \\
\hline
\end{tabular}

Fonte: Elaborado pelos autores.

A decisão de manter um artigo foi baseada na sua relevância com o tema proposto. As palavras-chave utilizadas para as publicações nacionais foram: "mídias sociais", "turismo" e "hotelaria", igualmente a frase completa "mídias sociais no turismo e na hotelaria". Notas de pesquisa, monografias, dissertações, teses, estudos de revisão de literatura, resenhas de livros e prefácios de editores foram excluídos. Ao 
final do processo de coleta de dados, uma amostra de 45 artigos nacionais foi gerada para a análise devido sua contribuição para a área.

Da mesma forma, para permitir a apresentação do estado atual das descobertas e discussões relacionadas com as mídias sociais na literatura sobre turismo e hotelaria em revistas e periódicos internacionais, utilizaram-se como palavras-chave "social media"; "hotel" e "tourism". Do universo de 110 artigos completos, foram elencados para este estudo o total de 33 trabalhos devido seu tema ser especificamente voltado ao turismo e à hotelaria (Tabela 2). Trabalhos que abordavam o tema central "mídia social" de abrangência genérica e descartavam turismo e hotelaria foram desconsiderados.

Tabela 2 - Artigos internacionais sobre mídias sociais no turismo e hotelaria.

\begin{tabular}{l|c|c}
\hline \multicolumn{1}{c|}{ Revistas Internacionais } & Quantidade & Ano \\
\hline Anuario Turismo y Sociedad & 1 & 2017 \\
\hline Asia Pacific Journal of Tourism Research & 1 & 2016 \\
\hline Business \& Economics Research Journal & 1 & 2017 \\
\hline Business Horizons & 1 & 2010 \\
\hline Consortium Journal of Hospitality and Tourism & 1 & 2014 \\
\hline Current Issues in Tourism & 1 & 2015 \\
\hline European Journal of Tourism Research & 1 & 2016 \\
\hline Global Journal of Enterprise Information System & 1 & 2016 \\
\hline Information and Communication Technologies in Tourism & 1 & 2008 \\
\hline Investigaciones Turísticas & 1 & 2015 \\
\hline International Journal of Hospitality Management & 1 & 2014 \\
\hline International Journal of Hospitality \& Tourism Administration & 1 & 2015 \\
\hline \multirow{2}{*}{ International Journal of Contemporary Hospitality Management } & 1 & 2014 \\
\hline Journal of Hospitality Marketing \& Management & 2 & 2016 \\
\hline Journal of Hospitality \& Tourism & 1 & 2014 \\
\hline Journal of Travel Research & 1 & 2016 \\
\hline \multirow{2}{*}{ TURyDES - Revista de Investigación en turismo y desarollo local } & 1 & 2015 \\
\hline Tourism and Hospitality International Journal & 1 & 2015 \\
\hline & 1 & 2009 \\
\hline Tourism \& Management Studies & 2 & 2013 \\
\hline & 2 & 2014 \\
\hline & 1 & 2015 \\
\hline & 1 & 2016 \\
\hline & 1 & 2008 \\
\hline & 1 & 2013 \\
\hline & 1 & 2014 \\
\hline & 3 & 2015 \\
\hline
\end{tabular}

Fonte: Elaborado pelos autores. 
A partir dos artigos nacionais e internacionais considerados para este estudo, foi traçada uma linha do tempo que abarcou os anos de 2006 a 2017. Deste levantamento, destaca-se que a primeira publicação realizada sobre mídias sociais é nacional, publicada no Seminário de Pesquisa em Turismo do Mercosul em 2006 e que traz uma investigação sobre a rede social Orkut e sua relação com o Ecoturismo1.

No final do processo de coleta de dados, uma amostra final de 78 artigos foi gerada para análise. Em termos de distribuição de datas, a maior concentração de estudos publicados em fontes nacionais foi nos anos de 2015 e 2016, com 12 e 09 respectivamente. No que se refere às fontes internacionais, o maior agrupamento de estudos se deu nos anos 2016, 2014 e 2015, com 10, 7 e 7 respectivamente. Até o período da pesquisa, a revista internacional Tourism \& Management Studies possui maior contribuição para o tema. Já no Brasil, os eventos de turismo e temas afins têm colaborado mais com essa área do conhecimento do que as publicações em revistas. Ressalta-se que neste artigo os autores não estão considerando a estratificação da qualidade da produção (Qualis) das revistas, periódicos e anais, fator que pode influenciar na decisão do pesquisador ao escolher um meio de divulgação de seu trabalho.

\section{Mídias sociais no turismo e na hotelaria}

As mídias sociais tornaram-se populares na atualidade; são ferramentas utilizadas pela grande maioria dos indivíduos, dos mais diversificados segmentos da sociedade, porém, é comum ainda existir equívocos quanto às terminologias "mídias sociais" e "redes sociais". Gonçalves (2013, p.30) explica que "os termos "redes sociais" e "mídias sociais" muitas vezes são usados como sinônimo, mas vale destacar que a primeira denominação está inserida dentro do conceito mais abrangente da última, respectivamente, como se fosse um segmento". Por isso, apresenta-se o Quadro 1 com definições de diferentes autores sobre os termos.

Quadro 1 - Quadro conceitual de mídias e redes sociais

\begin{tabular}{|c|c|c|c|}
\hline \multicolumn{2}{|r|}{ MÍDIAS SOCIAIS } & \multicolumn{2}{|r|}{ REDES SOCIAIS } \\
\hline Autor & Definição & Autor & Definição \\
\hline $\begin{array}{l}\text { Gretzel, Yuan } \\
\text { e } \\
\text { Fensenmaier } \\
(2000)\end{array}$ & $\begin{array}{lrr}\text { Mídias sociais são as } \\
\text { atividades, práticas } \\
\text { comportamentos } & \text { entre } \\
\text { comunidades de usuários que } \\
\text { compartilham na rede } \\
\text { informações, troca r de } \\
\text { conhecimentos e opiniões. }\end{array}$ & $\begin{array}{l}\text { Lima } \\
(2013, \\
6):\end{array}$ & $\begin{array}{l}\text { "As redes sociais, como o próprio } \\
\text { nome sugere, são sites que } \\
\text { disponibilizam ferramentas que } \\
\text { facilitam o convívio social e } \\
\text { compartilhamento de ideias, } \\
\text { pensamentos e visões entre as } \\
\text { pessoas, promovendo a criação ou } \\
\text { manutenção de vínculos entre os } \\
\text { indivíduos". }\end{array}$ \\
\hline
\end{tabular}

Continua

\footnotetext{
${ }^{1}$ Título do trabalho: Ecoturismo nas redes de relacionamentos: orkuturismo, mais um rótulo pósmoderno. Autoria de Laudo Natsul, mestre em ciência da comunicação - ECA-USP.

REUNA, Belo Horizonte - MG, Brasil, v.24, п.3, p. 64-79, Jul. - Set. 2019 - ISSN 2179-8834
} 
Quadro 1 - Quadro conceitual de mídias e redes sociais (continuação)

\begin{tabular}{|c|c|c|c|}
\hline \multicolumn{2}{|r|}{ MÍDIAS SOCIAIS } & \multicolumn{2}{|r|}{ REDES SOCIAIS } \\
\hline Autor & Definição & Autor & Definição \\
\hline $\begin{array}{l}\text { Cabral } \\
(2016, \text { p. 2) }\end{array}$ & $\begin{array}{l}\text { “[...] tecnologias e práticas } \\
\text { online usadas por pessoas ou } \\
\text { empresas para disseminar } \\
\text { conteúdo, provocando o } \\
\text { compartilhamento de opiniões, } \\
\text { ideias, experiências e } \\
\text { perspectivas”. }\end{array}$ & $\begin{array}{l}\text { Tomaél, } \\
\text { Alcará e Di } \\
\text { Chiara } \\
(2005, \text { p. 1) }\end{array}$ & $\begin{array}{l}\text { "Nas redes sociais, cada indivíduo tem } \\
\text { sua função e identidade cultural. Sua } \\
\text { relação com outros indivíduos vai } \\
\text { formando um todo coeso que } \\
\text { representa a rede. De acordo com a } \\
\text { temática da organização da rede, é } \\
\text { possível a formação de configurações } \\
\text { diferenciadas e mutantes". }\end{array}$ \\
\hline $\begin{array}{l}\text { Kaplan } \\
\text { Haenlein } \\
(2010)\end{array}$ & $\begin{array}{l}\text { Mídias sociais são definidas } \\
\text { como um grupo de aplicativos } \\
\text { baseados na internet que se } \\
\text { baseiam em fundamentos } \\
\text { ideológicos e tecnológicos de } \\
\text { Web 2.0, e que permitem a } \\
\text { criação e troca de Conteúdo } \\
\text { Gerado pelo Usuário (CGU). }\end{array}$ & $\begin{array}{l}\text { Ramos } \\
\text { (2010, } \\
115):\end{array}$ & $\begin{array}{l}\text { "As principais potencialidades das } \\
\text { redes sociais são o fato de ajudar a } \\
\text { fidelizar o cliente, através da criação } \\
\text { de uma página de fãs onde se } \\
\text { apresentam promoções; de angariar } \\
\text { seguidores e possíveis novos clientes, } \\
\text { através da publicidade "link-a-link"; } \\
\text { também permite a conversação entre } \\
\text { profissionais do setor, bem como o } \\
\text { diálogo entre fornecedores e clientes; } \\
\text { ajuda a promover o turismo, através da } \\
\text { partilha de experiências e de imagens; } \\
\text { apresenta oportunidades de negócio, } \\
\text { através de descontos para os } \\
\text { seguidores; permite a criação de uma } \\
\text { página própria, onde permite aos } \\
\text { clientes deixarem as suas } \\
\text { experiências e opiniões sobre a } \\
\text { estadia num determinado destino". }\end{array}$ \\
\hline $\begin{array}{l}\text { Telles (2010, } \\
\text { p. 3) }\end{array}$ & $\begin{array}{l}\text { “As mídias sociais são } \\
\text { plataformas na internet } \\
\text { construídas para permitir a } \\
\text { criação colaborativa de } \\
\text { conteúdo, a interação social e } \\
\text { o compartilhamento de } \\
\text { informações em diversos } \\
\text { formatos”. }\end{array}$ & $\begin{array}{l}\text { Cantinho, } \\
\text { Correia e } \\
\text { Ramos } \\
(2016, \quad p . \\
29)\end{array}$ & $\begin{array}{l}\text { "As redes sociais permitiram criar na } \\
\text { sociedade novas formas de } \\
\text { sociabilidade, através da procura e } \\
\text { partilha de informações, facilitando a } \\
\text { comunicação entre pessoas com } \\
\text { interesses comuns". }\end{array}$ \\
\hline
\end{tabular}

Fonte: Elaborado pelos autores.

O Quadro 1 demonstra que a evolução da internet propiciou o desenvolvimento de uma ferramenta de amplo poder de relacionamento pessoal e comercial, contribuindo tanto para a vida em sociedade quanto para os negócios. No que tange aos negócios, o poder de venda pelas empresas, bem como o poder de barganha pelos consumidores faz com que diariamente o mercado se atualize e encontre formas de inovar suas estratégias com o intuito de se relacionar e fidelizar seus clientes. Por isso, o estudo das redes sociais é de alta relevância para àqueles que almejam se especializar na área para conquistar seus objetivos. No quadro seguinte, Belo (2011) explica que as redes sociais, entre as suas variadas definições, podem ser classificadas em horizontais ou verticais, assim como, blogging, mundos virtuais, wikis e multimídia. 
Quadro 2 - Classificação das Redes Sociais.

\begin{tabular}{ll}
\hline \multicolumn{1}{c}{ Classificação } & \multicolumn{1}{c}{ Redes Sociais } \\
\hline Horizontais & Facebook, Bebo, Linkedln, Hi5, MySpace, Orkut. \\
Verticais & TripAdvisor, Virtual Tourist, Travelpod, LonelyPlan, Localyte. \\
Blogging & Twitter, Blogger. \\
Mundos Virtuais & SecondLife. \\
Wikis & Wikitravel, Wikipedia. \\
Multimédia & Youtube, Flickr, Slideshare. \\
\hline
\end{tabular}

Fonte: Adaptado de Belo (2011, p. 12).

A diferenciação entre as definições de redes sociais horizontais e verticais está associada ao conteúdo que é abordado e compartilhado entre os usuários; nas redes sociais horizontais os usuários compartilham e debatem diversos assuntos de seus interesses; já nas verticais, são debatidos assuntos específicos propostos por aquela rede social.

Para melhor compreensão do estudo das mídias sociais no turismo e hotelaria, - Quadro 3 apresenta os principais estudos relacionados na temática abordada conforme os critérios explicitados na metodologia e sintetizados na Tabela 2 (todas as publicações relacionadas às mídias sociais encontradas em revistas de turismo e hotelaria nacionais e internacionais foram pesquisadas e coletadas em diferentes bases de dados online, bem como todas as revistas e os anais de eventos da área mais conhecidos no país, usando as palavras-chave "social media"; "hotel" e "tourism").

Quadro 3 - Principais estudos sobre mídias sociais.

\begin{tabular}{|c|c|c|c|}
\hline $\begin{array}{l}\text { Autor(es), } \\
\text { ano }\end{array}$ & Objetivo(s) & Metodologia & Resultado(s) \\
\hline $\begin{array}{l}\text { Gretzel, Yuan } \\
\text { e } \\
\text { Fensenmaier } \\
(2000)\end{array}$ & $\begin{array}{l}\text { Identificar estratégias } \\
\text { eficazes r para } \\
\text { publicidade turística } \\
\text { na internet em } \\
\text { organizações de } \\
\text { marketing de destino } \\
\text { (DMOs). }\end{array}$ & Bibliográfica & $\begin{array}{l}\text { Os resultados indicam } \\
\text { que a tecnologia da } \\
\text { informação levou a uma } \\
\text { série de profundas } \\
\text { mudanças nos } \\
\text { pressupostos } \\
\text { subjacentes à estratégia } \\
\text { de comunicação. }\end{array}$ \\
\hline $\begin{array}{l}\text { Tuominen } \\
\text { (2011) }\end{array}$ & $\begin{array}{l}\text { Este estudo pretende } \\
\text { provar o efeito dos } \\
\text { comentários online } \\
\text { gerados pelo } \\
\text { consumidor sobre a } \\
\text { rentabilidade de um } \\
\text { hotel individual. }\end{array}$ & $\begin{array}{l}\text { Foi desenvolvido um exercício } \\
\text { de mineração de dados. Um } \\
\text { conjunto de hotéis foi definido } \\
\text { em combinação com as } \\
\text { estatísticas de receita dos } \\
\text { hotéis escolhidos. Análise do } \\
\text { conteúdo das revisões e } \\
\text { abordagens de análise } \\
\text { multivariada foram utilizadas } \\
\text { para entender os dados. }\end{array}$ & $\begin{array}{l}\text { Os resultados mostram } \\
\text { que existem correlações } \\
\text { entre o desempenho do } \\
\text { hotel e o número de } \\
\text { comentários fornecidos, } \\
\text { bem como com as } \\
\text { classificações dos } \\
\text { comentários. }\end{array}$ \\
\hline
\end{tabular}


Quadro 3 - Principais estudos sobre mídias sociais (continuação)

\begin{tabular}{|c|c|c|c|}
\hline $\begin{array}{c}\text { Autor(es), } \\
\text { ano }\end{array}$ & Objetivo(s) & Metodologia & Resultado(s) \\
\hline $\begin{array}{l}\text { Fotis, } \\
\text { Buhalis e } \\
\text { Rossides } \\
\text { (2012) }\end{array}$ & $\begin{array}{l}\text { Apresentar uma visão } \\
\text { abrangente do papel e } \\
\text { impacto das mídias } \\
\text { sociais no processo de } \\
\text { planejamento de viagens } \\
\text { de férias inteiras: antes, } \\
\text { durante e após a viagem, } \\
\text { fornecendo informações } \\
\text { sobre níveis de uso, } \\
\text { alcance de uso, nível de } \\
\text { influência e confiança. }\end{array}$ & $\begin{array}{l}\text { Pesquisa } \\
\text { bibliográfica, } \\
\text { pesquisa de } \\
\text { questionário online, } \\
\text { questões } \\
\text { pertinentes a ultima } \\
\text { viagem dos } \\
\text { respondentes no } \\
\text { universo de } 12 \\
\text { últimos meses. }\end{array}$ & $\begin{array}{l}\text { Os resultados sugerem que as } \\
\text { mídias sociais sas } \\
\text { predominantemente utilizadas } \\
\text { após as férias para o } \\
\text { compartilhamento de experiências. } \\
\text { Também é demonstrado que existe } \\
\text { uma forte correlação entre o nível } \\
\text { de influência percebido das mídias } \\
\text { sociais e as mudanças feitas em } \\
\text { planos de férias antes das decisões } \\
\text { finais. Além disso, é revelado que o } \\
\text { conteúdo gerado pelo usuário é } \\
\text { percebido como mais confiável } \\
\text { quando comparado aos sites } \\
\text { oficiais de turismo, agentes de } \\
\text { viagens e publicidade de mídia de } \\
\text { massa. }\end{array}$ \\
\hline $\begin{array}{l}\text { Fotis, } \\
\text { Buhalis e } \\
\text { Rossides } \\
\text { (2012) }\end{array}$ & $\begin{array}{l}\text { Apresentar uma visão } \\
\text { abrangente do papel e } \\
\text { impacto das mídias } \\
\text { sociais no processo de } \\
\text { planejamento de viagens } \\
\text { de férias inteiras: antes, } \\
\text { durante e após a viagem, } \\
\text { fornecendo informações } \\
\text { sobre níveis de uso, } \\
\text { alcance de uso, nível de } \\
\text { influência e confiança. }\end{array}$ & $\begin{array}{l}\text { Pesquisa } \\
\text { bibliográfica, } \\
\text { pesquisa de } \\
\text { questionário online, } \\
\text { questões } \\
\text { pertinentes a ultima } \\
\text { viagem r dos } \\
\text { respondentes no } \\
\text { universo de } 12 \\
\text { últimos meses. }\end{array}$ & $\begin{array}{l}\text { Os resultados sugerem que as } \\
\text { mídias sociais são } \\
\text { predominantemente utilizadas } \\
\text { após as férias para o } \\
\text { compartilhamento de experiências. } \\
\text { Também é demonstrado que existe } \\
\text { uma forte correlação entre o nível } \\
\text { de influência percebido das mídias } \\
\text { sociais e as mudanças feitas em } \\
\text { planos de férias antes das decisões } \\
\text { finais. Além disso, é revelado que o } \\
\text { conteúdo gerado pelo usuário é } \\
\text { percebido como mais confiável } \\
\text { quando comparado aos sites } \\
\text { oficiais de turismo, agentes de } \\
\text { viagens e publicidade de mídia de } \\
\text { massa. }\end{array}$ \\
\hline $\begin{array}{l}\text { Boaria, } \\
\text { Raye e } \\
\text { Felini } \\
(2013)\end{array}$ & $\begin{array}{l}\text { O presente estudo tem } \\
\text { como objetivo principal } \\
\text { apresentar as mídias } \\
\text { sociais e as novas } \\
\text { ferramentas de marketing } \\
\text { utilizadas no turismo pela } \\
\text { hotelaria e seus } \\
\text { consumidores. }\end{array}$ & $\begin{array}{l}\text { Exploratório } \\
\text { utilizando } \\
\text { pesquisa } \\
\text { bibliográfica como } \\
\text { técnica de coleta de } \\
\text { dados. }\end{array}$ & $\begin{array}{l}\text { Em sua revisão teórica examina a } \\
\text { influência das mídias sociais no } \\
\text { setor de turismo, especificamente } \\
\text { na hotelaria, destacando } \\
\text { estratégias e ferramentas mais } \\
\text { utilizadas. Também explana sobre } \\
\text { as intenções comportamentais do } \\
\text { uso de redes sociais para fins de } \\
\text { planejamento de viagem. }\end{array}$ \\
\hline
\end{tabular}


Quadro 3 - Principais estudos sobre mídias sociais (continuação)

\begin{tabular}{|c|c|c|c|}
\hline $\begin{array}{c}\text { Autor(es), } \\
\text { ano }\end{array}$ & Objetivo(s) & Metodologia & Resultado(s) \\
\hline $\begin{array}{l}\text { Gonçalves } \\
(2013)\end{array}$ & $\begin{array}{l}\text { Analisar o uso da Rede } \\
\text { Social Facebook como } \\
\text { ferramenta de marketing } \\
\text { dos destinos turísticos. }\end{array}$ & $\begin{array}{l}\text { A pesquisa tem } \\
\text { caráter exploratório, } \\
\text { utiliza de fontes } \\
\text { bibliográficas e } \\
\text { eletrônicas e segue } \\
\text { em sua metodologia } \\
\text { uma abordagem } \\
\text { quali-quantitativa. }\end{array}$ & $\begin{array}{l}\text { Pôde-se identificar que as } \\
\text { fanpages dos destinos } \\
\text { apresentaram melhor atuação na } \\
\text { rede, o que é refletido no } \\
\text { engajamento dos seus usuários } \\
\text { e na avaliação feita para } \\
\text { identificar o "Campeão" das } \\
\text { mídias sociais. Também } \\
\text { identificou-se vícios negativos de } \\
\text { algumas páginas, como o } \\
\text { excesso de postagens por dia, o } \\
\text { compartilhamento compulsivo de } \\
\text { conteúdos de outras páginas e } \\
\text { até uma inúmera quantidade de } \\
\text { dias sem publicação de } \\
\text { conteúdo, afetando diretamente } \\
\text { a audiência da página. }\end{array}$ \\
\hline $\begin{array}{l}\text { Linnes, } \\
\text { Kowalski, } \\
\text { Lema, Lam e } \\
\text { Agrusa } \\
\text { (2014) }\end{array}$ & $\begin{array}{l}\text { Examinar como as mídias } \\
\text { sociais se conectam } \\
\text { tecnologicamente e } \\
\text { interage com clientes } \\
\text { para comentários, } \\
\text { análises e pesquisas, } \\
\text { para alcançar mais } \\
\text { usuários. }\end{array}$ & $\begin{array}{l}\text { Pesquisa } \\
\text { bibliográfica, } \\
\text { Entrevistas, Hotéis } \\
\text { do Havaí. }\end{array}$ & $\begin{array}{l}\text { Apesar de ter um relacionamento } \\
\text { com o site de revisão é } \\
\text { importante construir um } \\
\text { relacionamento com o revisor } \\
\text { também. A gestão de respostas } \\
\text { para comentários são } \\
\text { importantes para cerca de } 70 \% \\
\text { dos entrevistados. }\end{array}$ \\
\hline $\begin{array}{l}\text { Mellinas, } \\
\text { María- } \\
\text { Dolores } \\
\text { García } \\
\text { (2014) }\end{array}$ & $\begin{array}{l}\text { Analisar o nível de uso } \\
\text { das principais redes } \\
\text { sociais nos hotéis } \\
\text { costeiros espanhóis, que } \\
\text { não pertencem a grandes } \\
\text { cadeias hoteleiras. }\end{array}$ & $\begin{array}{l}\text { Pesquisaram-se } \\
\text { hotéis da costa } \\
\text { espanhola através } \\
\text { do Booking, } \\
\text { escolheram-se } \\
\text { hotéis } \\
\text { independentes ou } \\
\text { de redes pequenas. }\end{array}$ & $\begin{array}{l}\text { Verificou-se que os hotéis com } \\
\text { maior número de estrelas } \\
\text { tendem a usar em maior } \\
\text { proporção de redes sociais. Além } \\
\text { disso, a porcentagem de } \\
\text { estabelecimentos com } \\
\text { deficiências na gestão das redes } \\
\text { sociais (de acordo com os } \\
\text { critérios estabelecidos) é menor } \\
\text { nos hotéis com mais estrelas. }\end{array}$ \\
\hline $\begin{array}{l}\text { Law, } \\
\text { Buhalis e } \\
\text { Cobanoglu } \\
(2014)\end{array}$ & $\begin{array}{l}\text { O objetivo deste trabalho } \\
\text { é estabelecer o progresso } \\
\text { da Tecnologia da } \\
\text { informação } \quad \text { e } \\
\text { comunicação (TIC) com } \\
\text { base em uma revisão de } \\
\text { artigos publicados em } \\
\text { revistas de turismo e } \\
\text { hospitalidade entre } \\
2009 \text { e } 2013 \text {. }\end{array}$ & $\begin{array}{l}\text { Pesquisa } \\
\text { Bibliográfica } \\
\text { baseada em três } \\
\text { principais bancos de } \\
\text { dados. }\end{array}$ & $\begin{array}{l}\text { A análise do conteúdo mostrou } \\
\text { que as indústrias de } \\
\text { hospitalidade e turismo } \\
\text { utilizaram as TIC em diferentes } \\
\text { unidades funcionais para } \\
\text { diferentes aplicações. Isso, por } \\
\text { sua vez, indica sua ampla } \\
\text { adoção na indústria. }\end{array}$ \\
\hline
\end{tabular}


Quadro 3 - Principais estudos sobre mídias sociais (continuação)

\begin{tabular}{|c|c|c|c|}
\hline Autor(es), & Objetivo(s) & Metodologia & Resultado(s) \\
\hline $\begin{array}{l}\text { Buhalis e } \\
\text { Mamalakis } \\
\text { (2015) }\end{array}$ & $\begin{array}{l}\text { O objetivo deste trabalho } \\
\text { é explorar práticas de } \\
\text { medição de marketing } \\
\text { online e para criar uma } \\
\text { estrutura que auxilie a } \\
\text { mensurabilidade das } \\
\text { mídias sociais. }\end{array}$ & $\begin{array}{l}\text { Estudo de } \\
\text { pesquisa. A } \\
\text { atividades das mídias } \\
\text { sociais do Princess } \\
\text { Adrianna Resort and } \\
\text { Spa Hotel, em Rhodes, } \\
\text { Gréciar r Busca } \\
\text { desenvolver ruma } \\
\text { estrutura de técnicas e } \\
\text { medidas para avaliar a } \\
\text { eficácia. }\end{array}$ & $\begin{array}{l}\text { O resultado identificou retornos } \\
\text { financeiros e não financeiros. } \\
\text { Verificou-se claramente que as } \\
\text { redes sociais podem realmente } \\
\text { gerar receitas para um } \\
\text { negócio. Todas as plataformas } \\
\text { de promoção podem ser } \\
\text { utilizadas como pontos de } \\
\text { venda ou como ferramentas } \\
\text { promocionais. }\end{array}$ \\
\hline $\begin{array}{l}\text { Buhalis e } \\
\text { Mamalakis } \\
\text { (2015) }\end{array}$ & $\begin{array}{l}\text { O objetivo deste trabalho } \\
\text { é explorar práticas de } \\
\text { medição de marketing } \\
\text { online e para criar uma } \\
\text { estrutura que auxilie a } \\
\text { mensurabilidade das } \\
\text { mídias sociais. }\end{array}$ & $\begin{array}{l}\text { Estudo de caso. A } \\
\text { pesquisa } \\
\text { atividades das mídias } \\
\text { sociais do Princess } \\
\text { Adrianna Resort and } \\
\text { Spa Hotel, em Rhodes, } \\
\text { Grécia. Busca } \\
\text { desenvolver uma } \\
\text { estrutura de técnicas e } \\
\text { medidas para avaliar a } \\
\text { eficácia. }\end{array}$ & $\begin{array}{l}\text { O resultado identificou retornos } \\
\text { financeiros e não financeiros. } \\
\text { Verificou-se claramente que as } \\
\text { redes sociais podem realmente } \\
\text { gerar receitas para um } \\
\text { negócio. Todas as plataformas } \\
\text { de promoção podem ser } \\
\text { utilizadas como pontos de } \\
\text { venda ou como ferramentas } \\
\text { promocionais. }\end{array}$ \\
\hline $\begin{array}{l}\text { Thomaz, Biz } \\
\text { e Bettoni } \\
\text { (2015) }\end{array}$ & $\begin{array}{l}\text { Analisar a gestão e o } \\
\text { monitoramento em } \\
\text { mídias sociais pelas } \\
\text { Destination Management } \\
\text { Organizations (DMO) da } \\
\text { cidade de Curitiba-PR, à } \\
\text { saber: Instituto Municipal } \\
\text { de Turismo de Curitiba e } \\
\text { Curitiba Região e Litoral } \\
\text { Convention \& Visitors } \\
\text { Bureau. }\end{array}$ & $\begin{array}{l}\text { Abordagem qualitativa, } \\
\text { foram utilizadas as } \\
\text { técnicas de pesquisa } \\
\text { bibliográfica } \\
\text { entrevista } \\
\text { semiestruturada para } \\
\text { coleta de dados. }\end{array}$ & $\begin{array}{l}\text { Constataram-se que as DMO } \\
\text { não realizam gestão e } \\
\text { monitoramento de mídias } \\
\text { sociais com uso de software } \\
\text { e/ou técnicas de mineração de } \\
\text { dados, sendo estes fatores } \\
\text { críticos segundo a literatura de } \\
\text { referência. Entretanto, ambas } \\
\text { utilizam a ferramenta analítica } \\
\text { oferecida pelo Facebook para } \\
\text { monitorar e analisar or o } \\
\text { desempenho das ações e } \\
\text { publicações. }\end{array}$ \\
\hline $\begin{array}{l}\text { Mellinas, } \\
\text { María- } \\
\text { Dolores } \\
\text { García } \\
(2016)\end{array}$ & $\begin{array}{l}\text { O objetivo deste trabalho } \\
\text { é descobrir se a } \\
\text { utilização eficiente } \\
\text { dessas ferramentas de } \\
\text { mídias sociais pode ter } \\
\text { algum tipo em relação à } \\
\text { pontuação obtida pelos } \\
\text { hotéis e, portanto, com } \\
\text { gestão eficiente. }\end{array}$ & $\begin{array}{l}\text { Análise das opiniões } \\
\text { dos hóspedes no } \\
\text { TripAdvisor e Booking, } \\
\text { observando } \\
\text { pontuações diferentes } \\
\text { dependendo sobre o } \\
\text { uso de redes sociais. }\end{array}$ & $\begin{array}{l}\text { Os dados mostram que em } \\
\text { geral o uso eficiente de redes } \\
\text { sociais acarreta em uma } \\
\text { pontuação mais alta do hotel } \\
\text { nos sites de avaliações. }\end{array}$ \\
\hline $\begin{array}{l}\text { Cabral } \\
(2016)\end{array}$ & $\begin{array}{l}\text { Identificar as mídias } \\
\text { sociais utilizadas pelos } \\
\text { meios de hospedagem } \\
\text { da cidade de Foz do } \\
\text { lguaçu. }\end{array}$ & $\begin{array}{l}\text { Análise bibliográfica e } \\
\text { documental, e também } \\
\text { o uso da técnica de } \\
\text { observação } \\
\text { assistemática. }\end{array}$ & $\begin{array}{l}\text { Verificou-se que as mídias } \\
\text { sociais utilizadas pelas } \\
\text { empresas hoteleiras da cidade } \\
\text { de Foz do Iguaçu são rede } \\
\text { social, blog, imagem, vídeo, } \\
\text { comunicação por voz e dentre } \\
\text { estas destaque para a rede } \\
\text { social utilizada pela maioria } \\
\text { dos estabelecimentos. }\end{array}$ \\
\hline
\end{tabular}


Quadro 3 - Principais estudos sobre mídias sociais (continuação)

\begin{tabular}{|c|c|c|c|}
\hline Autor(es), & Objetivo(s) & Metodologia & Resultado(s) \\
\hline $\begin{array}{l}\text { Boaria } \\
\text { Ortiz } \\
(2016)\end{array}$ & $\begin{array}{l}\text { Identificar de que forma a } \\
\text { internet influencia na } \\
\text { escolha do turista de Foz } \\
\text { do Iguaçu/Pr. }\end{array}$ & $\begin{array}{l}\text { Trata-se de uma } \\
\text { pesquisa quantitativa, } \\
\text { onde a coleta de dados } \\
\text { foi realizada por meio de } \\
\text { questionário, utilizando a } \\
\text { escala Likert de } 5 \\
\text { pontos. }\end{array}$ & $\begin{array}{l}\text { Constatou-se que } \\
\text { consumidor vem utilizando } \\
\text { cada vez mais a internet para } \\
\text { planejar, escolher e comprar } \\
\text { os serviços turísticos, sendo, } \\
\text { muitas vezes, influenciados } \\
\text { por comentários e opiniões de } \\
\text { seu círculo social. }\end{array}$ \\
\hline $\begin{array}{l}\text { Cantinho, } \\
\text { Correia e } \\
\text { Ramos } \\
(2016)\end{array}$ & $\begin{array}{l}\text { Identificar os fatores } \\
\text { conducentes à utilização } \\
\text { de redes sociais online, } \\
\text { em hotéis de } 4 \text { e } 5 \\
\text { estrelas do Algarve, os } \\
\text { seus benefícios es e } \\
\text { desafios; analisar o } \\
\text { alcance da presença do } \\
\text { hotel nas redes sociais, } \\
\text { através das métricas } \\
\text { utilizadas para o efeito; } \\
\text { verificar se as redes } \\
\text { sociais apresentam uma } \\
\text { oportunidade como } \\
\text { plataforma para distribuir } \\
\text { informação, fazer } \\
\text { reservas e criar relações } \\
\text { mais próximas, mais } \\
\text { pessoais e de confiança, } \\
\text { entre hotéis e clientes. }\end{array}$ & $\begin{array}{l}\text { Pesquisa bibliográfica, } \\
\text { aplicação de um } \\
\text { questionário composto } \\
\text { por } 29 \text { perguntas, o qual } \\
\text { foi enviado por correio } \\
\text { eletrônico no ano de } \\
2014 \text { para as } 160 \\
\text { unidades hoteleiras que } \\
\text { constituem o universo. } \\
\text { No momento da } \\
\text { elaboração do estudo } \\
\text { obteve-se } 98 \text { respostas, } \\
\text { o que representa } \\
61,25 \% \text { de taxa de } \\
\text { resposta. }\end{array}$ & $\begin{array}{l}\text { Os resultados deste estudo } \\
\text { permitiram concluir que os } \\
\text { estabelecimentos hoteleiros } \\
\text { utilizam as redes sociais } \\
\text { online para se comunicar com } \\
\text { os clientes; criar confiança; } \\
\text { conhecer tendências. No } \\
\text { entanto, encontram-se pouco } \\
\text { preparados para estar nos } \\
\text { meios sociais digitais, não } \\
\text { realizam uma análise } \\
\text { aprofundada por falta de } \\
\text { conhecimento para utilizar os } \\
\text { programas de métricas, } \\
\text { reduzidos recursos humanos } \\
\text { e falta de orçamento. }\end{array}$ \\
\hline $\begin{array}{l}\text { Silva } \\
\text { Brito } \\
(2016)\end{array}$ & $\begin{array}{l}\text { Evidenciar a importância } \\
\text { das mídias sociais na } \\
\text { avaliação de eventos, } \\
\text { destacando o Mossoró } \\
\text { Cidade Junina de } \\
\text { Mossoró-RN, uma festa } \\
\text { junina tradicional do } \\
\text { estado, buscando analisar } \\
\text { o evento a partir da } \\
\text { percepção rro dos } \\
\text { participantes. }\end{array}$ & $\begin{array}{l}\text { Caráter descritivo e } \\
\text { exploratório, com } \\
\text { análise quali-quantitativa } \\
\text { por meio de pesquisas } \\
\text { bibliográficas, e colheita } \\
\text { de dados na internet. }\end{array}$ & $\begin{array}{l}\text { Conclui-se que a partir dos } \\
\text { resultados, o Evento Mossoró } \\
\text { Cidade Junina foi avaliado } \\
\text { com maior frequência de } \\
\text { forma positiva, entretanto, } \\
\text { vale ressaltar que, a } \\
\text { frequência de forma negativa } \\
\text { em três das quatro categorias } \\
\text { analisadas é alta, revelando- } \\
\text { se assim que providências } \\
\text { para melhoria devem ser } \\
\text { tomadas para os eventos } \\
\text { futuros. }\end{array}$ \\
\hline
\end{tabular}

Fonte: Elaborado pelos autores.

O Quadro 3 apresenta diversos estudos que mostram a relevância da utilização das mídias sociais pelas empresas como ferramentas para a divulgação, comunicação, interação e vendas dos seus produtos e serviços. Gretzel, Yuan e Fensenmaier (2000), por exemplo, estudaram os efeitos do surgimento da internet e as mudanças ocorridas na estrutura do setor de publicidade, prevendo que alterações mais profundas estariam a caminho. Embora em sua investigação tais estudiosos ainda não mencionassem as mídias sociais, eles já reconheciam o avanço da internet 
na divulgação, nos serviços e vendas, independendo da localização geográfica, a partir de uma análise do interesse dos consumidores.

Fotis, Buhalis e Rossides (2012) apontam que existe uma forte correlação entre o nível de influência percebido das mídias sociais e as mudanças feitas em planos de férias antes das decisões finais, acrescentando que são predominantemente utilizadas após as férias para o compartilhamento de experiências. Corroborando, Boaria e Ortiz (2016) constataram a utilização cada vez mais frequente da internet pelo consumidor para planejamento da viagem, escolha e compra de produtos e serviços turísticos, onde muitas vezes esse consumidor torna-se influenciado por comentários e opiniões gerados em sua rede social. Tal influência é conhecida como "relação interpessoal online" ou "comunicação boca a boca online".

Tendo em vista a potencialidade das mídias sociais, o setor de meios de hospedagem precisa estar atento às oportunidades que essas mídias ofertam. As investigações de Buhalis e Mamalakis (2015), Cantinho, Correia e Ramos (2016), Mellinas, María-Dolores e García (2014) e María-Dolores e García (2016) contribuíram para a afirmar que principalmente os hotéis que possuem maiores números de estrelas estão fazendo uso das mídias sociais com o propósito de efetuar promoções, vendas, comunicação com o cliente, criação de confiança e divulgação. Além do retorno financeiro que a utilização das mídias sociais possibilita, nos hotéis com maior quantidade de estrelas é também onde se percebe a menor deficiência na gestão do uso das mídias sociais, sendo que o uso eficiente de redes sociais acarreta em uma pontuação mais alta dos hotéis nos sites de avaliações. Além disso, Cantinho, Correia e Ramos (2016) alertam que os hotéis demonstram pouco preparo para estarem presentes nas mídias sociais, pois não realizam uma análise aprofundada por falta de conhecimento para utilizar os programas de métricas, constatação essa que vai de encontro aos resultados do estudo de Thomaz, Biz e Bettoni (2015) que apontam a falta de gestão e monitoramento de mídias sociais com uso de software e/ou técnicas de mineração de dados pelas Destination Management Organizations (DMO) ou Organizações de Marketing de Destino da cidade de Curitiba/PR.

Nesse sentido, torna-se importante ressaltar que somente a presença do meio de hospedagem nas mídias sociais não garante uma boa imagem frente ao mercado consumidor e potencial. Linnes et al. (2014) concluíram que além da necessidade dos hotéis manterem um relacionamento com os sites de avaliações de viagens, também se torna importante construir um contato mais próximo com os usuários, pois $70 \%$ dos gestores hoteleiros entrevistados no Havaí consideram importante a manutenção de respostas por parte dos meios de hospedagem para seus comentários e avaliações. Do ponto de vista dos usuários, dados de uma pesquisa realizada pela Momondo (buscador de passagens aéreas e reservas de hotéis) confirmam que cerca de $60 \%$ dos brasileiros buscam inspiração para planejar viagens em sites especializados e $45 \%$ também recorrem às redes sociais para o planejamento de suas férias (apud HOSTELTUR, 2016).

As mídias sociais, segundo os autores estudados, apresentam atualmente um grande protagonismo no cotidiano de empresas e clientes, e entre elas destacam-se como possíveis ferramentas a serem exploradas pelos empreendimentos hoteleiros, o Facebook, o Instagram, o TripAdvisor, o Twitter e o WhatsApp. Todas promovem a interação social por meio de troca de mensagens, compartilhamento de fotos, vídeos, organização de eventos, criação de grupo e comunidades específicas, compartilhamento de relatos de experiências, dentre outras funções. Elas possibilitam RELUNA, Belo Horizonte - MG, Brasil, v.24, n.3, p. 64-79, Jul. - Set. 2019 - ISSN 2179-8834 
aos usuários manterem contatos com amigos, familiares, colegas de trabalho e até mesmo manter vínculo com instituições públicas e privadas, que é o caso das empresas de turismo e hotelaria. Inclusive, é possível observar nessas mídias sociais propagandas de produtos e serviços de diversas marcas de empreendimentos. Do mesmo modo, Mellinas, María-Dolores e García (2016) afirmam que o uso de redes sociais por parte das empresas é algo cada vez mais frequente, destacando-se especialmente o setor hoteleiro; os autores ainda consideram que o uso de redes sociais quando feito da forma adequada, denota uma gestão eficiente de um meio de hospedagem.

\section{Considerações finais}

Pode-se observar na literatura abordada que a tecnologia desempenha um papel vital no dia a dia das pessoas no século XXI. Devido à popularidade da internet e dos smartphones, as mídias sociais tem alterado o comportamento do consumidor e exerce um forte impacto nos negócios do turismo. Embora a importância estratégica das mídias sociais tenha sido reconhecida tanto pela academia quanto pelo mercado, faz-se necessário entender quais áreas podem ser mais estudadas no futuro para diminuir as lacunas no conhecimento e ajudar os profissionais a adotarem e responder melhor a esse fenômeno emergente.

Desse modo, a presente pesquisa buscou, por meio de revisão bibliográfica, encontrar diferentes variáveis que tem sido investigadas sobre as de mídias sociais no turismo e na hotelaria. Identificou-se que os pesquisadores estudados abordaram cinco amplas variáveis: características das mídias sociais; como ocorre a interação com as mídias sociais; o impacto esperado e gerado pelas mídias sociais pelas empresas e pelos consumidores; a relação interpessoal online ou comunicação boca a boca online, a partir de comentários gerados pelos usuários, e, a personalização. Tais variáveis se relacionam com as correntes da gestão e do marketing, interferindo sobremaneira na rotina das empresas.

As mídias sociais fornecem várias plataformas, permitindo que a comunicação boca a boca seja criada e distribuída em uma velocidade muito rápida. Por ser uma mídia popular com informações sobre viagens, o TripAdvisor, por exemplo, possui informações compartilhadas pelos viajantes de todo o mundo sobre sua experiência de viagem em relação a um destino turístico, hotel ou serviços de restaurante. Essas avaliações online podem ser classificadas como propagandas positivas ou negativas, de acordo com a expectativa e percepção que o cliente obteve. Neste sentido, a gestão de uma empresa hoteleira pode beneficiar-se com as experiências compartilhadas, desde que se prepare para um bom atendimento antes, durante e depois da compra pelo cliente. A divulgação e a criação de conteúdo, assim como as atitudes da empresa para otimizar a gestão têm influência direta com todas as variáveis (características, interação, impacto, relação interpessoal online e personalização), impossibilitando, neste caso, trabalhar com cada uma isoladamente.

Pesquisadores observaram que as mídias sociais são ferramentas que podem ser utilizadas como inteligência de mercado, sendo um grande potencial de negócios para a empresa, pois impactam a imagem, produto, popularidade, vendas, preços e o valor da marca. As empresas podem utilizar um mecanismo de feedback online a fim 
de obter uma compreensão mais profunda das expectativas e do comportamento dos clientes.

Os resultados da pesquisa também indicaram que o comportamento das pessoas na utilização das mídias sociais está associado a vários fatores, incluindo traços de personalidade, características sociodemográficas, conhecimento tecnológico em softwares, computadores e smartphones, além de hábitos de uso.

Por meio da literatura abordada neste estudo, confirma-se que a finalidade das mídias sociais, tradicionalmente, é para os indivíduos agrupar-se com outros onde exista uma relação de opiniões afins, de amizade (quando uma rede social é utilizada para ajudar amigos e parentes a tomar decisões ou ajudar empresas) e de corporativismo, com as relações de trabalho. Ademais, elas permitem benefícios sociais, como entretenimento e até mesmo incentivos econômicos (por exemplo, ganhar pontos ou recompensas). A ocorrência destas características se justifica devido as mídias sociais criarem valores intelectuais, sociais e culturais para seus membros.

Um fator que dificultou a pesquisa, entretanto, não a limitou devido aos critérios utilizados pelos autores, foi a dificuldade encontrada em pesquisar as publicações nos anais dos eventos por meio das palavras-chaves. Neste caso, os autores se dedicaram na busca de artigos inseridos em diferentes grupos de trabalhos (GTs) ou áreas temáticas, verificando minuciosamente a abordagem de cada publicação.

Embora este estudo tenha apresentado um número significativo de estudos na temática (total de 78), este montante ainda é tímido considerando que esta pesquisa não delimitou um período, e sim compreendeu a todas as publicações encontradas online, constatando que a temática "mídias sociais no turismo e hotelaria" ainda atrai poucos pesquisadores. Este fato levou os autores deste artigo ao não direcionamento apenas à hotelaria (ideia inicial da pesquisa), englobando também o turismo devido à falta de estudos específicos sobre a área hoteleira.

Por fim, a partir das lacunas encontradas, os autores sugerem 0 desdobramento das variáveis identificadas, ampliando a área do conhecimento e contribuindo com a academia e com o mercado turístico e hoteleiro.

\section{Referências}

BELO, A. L. L. G. O potencial dos sites de redes sociais no desempenho das pequenas e médias empresas da região do Algarve. 2011. 119 f. Dissertação (Curso de Mestrado em Economia da Inovação e Empreendedorismo), Universidade do Algarve, Faro: Portugal, 2011.

BOARIA, F; RAYE, R. L; FELINI, A. Mídias Sociais: uma reflexão sobre as novas ferramentas de marketing na hotelaria. VII Fórum Internacional de Turismo do Iguassu, Foz do Iguaçu - Paraná - Brasil, 2013.

F.; ORTIZ, T. B. O Turismo e a Web - Uma Análise sobre a Influência da Internet nas Escolhas do Turista de Foz do Iguaçu/Pr. Fórum Internacional do Iguassu, v 10, 2016. 
BUHALIS, D.; MAMALAKIS, E. Retorno Social Media Return on Investment and Performance Evaluation in the Hotel Industry Context. Information and Communication Technologies in Tourism, p. 241-253, fev. 2015.

CABRAL, S. G. As mídias sociais utilizadas pelos meios de hospedagem da cidade de Foz do Iguaçu - PR. XIII Seminário ANPTUR 2016.

CANTINHO, G. M. R., CORREIA, M. B. \& RAMOS, C. M. Q. As redes sociais online nos hotéis de 4 e 5 estrelas do Algarve. Tourism and Hospitality International Journal, 7(1), 27-48, 2016.

EMARKETER. eMarketer Report: Worldwide Social Network Users Update: eMarketer's Estimates and Forecast for 2016-2021, with a Focus on Instagram. Published: January 08, 2018. Disponível em: < https://www.emarketer.com/Report/Worldwide-Social-Network-Users-UpdateeMarketers-Estimates-Forecast-20162021-with-Focus-on-Instagram/2002170>. Acesso em: 22 de abril de 2018.

FACEBOOK. Agora sua marca pode alcançar até 2 bilhões de pessoas por mês no Facebook. Disponível em: <https://www.facebook.com/business/news/facebook2-bilhoes\#>. Acesso em: 22 de abril de 2018.

FOTIS, J.; BUHALIS, D.; ROSSIDES, N. (2012). Social Media Use and Impact during the Holiday Travel Planning Process. Disponível em: < https://link.springer.com/chapter/10.1007\%2F978-3-7091-1142-0_2>. Acesso em: 20 ago. 2017.

GONÇALVES, M. B. "Criatividade em Campo": uso da mídia social como ferramenta estratégica de marketing dos destinos sedes da Copa 2014. 2013. 121 f. Dissertação (Curso de Mestrado em Turismo), Universidade Federal do Rio Grande do Norte, Natal: Rio Grande do Norte, 2013.

GRETZEL, U.; YUAN, Y. ; FENSENMAIER, D. Preparing for the New Economy: Advertising Strategies and Change in Destination Marketing organizations. Journal of Travel Research. 39, 149-156, 2000.

. Sessenta por cento dos brasileiros utilizam sites de viagens para
planejar férias, diz estudo. 2016 . Disponível em:
https://www.hosteltur.com.br/119200_sessenta-cento-dos-brasileiros-utilizam-sites-
viagens-planejar-ferias-diz-estudo.html>. Acesso em: 22 abr. 2018.

KAPLAN, A.; HAENLEIN, M. Users of the world, unite! The challenges and opportunities of Social Media. Business Horizons, 53(1), 59-68, 2010.

LAW, R.; BUHALIS, D.; COBANOGLU, C. Progress on information and communication technologies in hospitality and tourism. International Journal of Contemporary Hospitality Management, Vol. 26 Iss 5 pp. 727 - 750, 2014.

LIMA, B. S. O uso da internet na venda e divulgação dos produtos e serviços de hospedagem: o caso de Dourados/MS - Brasil. Revista Hospitalidade, São Paulo, v. 10, n. 2, p. 387-407, 2013. 
LINNES, C.; KOWALSKI, P.; LEMA, J; LAM, W.; AGRUSA, J. Social Media and Technology: The Influence on Hawaii's Hotels. Consortium Journal of Hospitality and Tourism. p 54-73, 2014

MELLINAS, J. P.; MARÍA-DOLORES, S. M.; GARCÍA, J. B. Uso de las redes sociales en los hoteles de la costa española. Investigaciones Turísticas № 7 , enero-junio año, 87-101, 2014.

, J. P.; MARÍA-DOLORES, S. M.; GARCÍA, J. B. El uso de redes sociales por los hoteles como indicativo de gestión eficiente. Tourism \& Management Studies, 12 (2), 78-83, 2016.

O'CONNOR, P.; MURPHY, J. Research on information technology in the hospitality industry. International Journal of Hospitality Management, 23(5), 473-484, 2004.

RAMOS, C. Sistemas de informação para a gestão turística. Revista Encontros Científicos - Tourism \& Management Studies, 107-116, 2010.

SILVA, D. S.; BRITO, G. C. Mossoró Cidade Junina: Mídias Sociais na Avaliação de Eventos. XIII Seminário ANPTUR 2016.

TELLES, A. A Revolução das Mídias Sociais - cases, conceitos, dicas e ferramentas. São Paulo: M. Books, 2010.

THOMAZ, G. M.; BIZ, A. A.; BETTONI, E. M. Análise da gestão e monitoramento em mídias sociais pelas Destination Management Organizations (DMO) de Curitiba-PR. XII Seminário ANPTUR 2015.

TOMAÉL, M. I; ALCARÁ, A. R; DI CHIARA, I. G. Das redes sociais à inovação. Ci. Inf., Brasília, v. 34, n. 2, p. 93-104, maio/ago. 2005.

TUOMINEN, P. The Influence of TripAdvisor Consumer-Generated Travel Reviews on Hotel Performance. University of Hertfordshire Business School Working Paper (2011).

TWITTER. Uso do Twitter / Dados da Empresa. Disponível em: < https://about.twitter.com/pt/company>. Acesso em: 22 de abril de 2018. 